\title{
KONTEKSTUALISASI KISAH MARYAM DI DALAM AL-QUR'AN SEBAGAI BASIS TELADAN GENERASI MUDA MUSLIM ERA KONTEMPORER
}

\author{
Tazkia Anugraheni Perdana \\ Universitas Ahmad Dahlan \\ tazkiaperdana@gmail.com
}

\begin{abstract}
One of the many stories that Allah tells in the Qur'an is the story of Maryam bint Imran, she was a tough woman and at the same time the mother of Prophet Isa. It has many features and lessons we can take from it. Knowledge of Islamic figures themselves is very minimal. Some people only think that these shop figures will only be discussed in religious studies and not practiced in everyday life. Unfortunately, if we practice what is contained in the al-Qur'an our life will be orderly and directed. The purpose of this research is to reintroduce the people of Maryam binti Imran who may have partly forgotten or even did not know anything about this. The method in this research is library research
\end{abstract}

Keyword: life, maryam binti imran, patient, woman

\section{Abstrak}

Salah satu dari sekian banyak kisah yang Allah ceritakan di al-Qur'an adalah kisah Maryam binti Imran ia adalah perempuan yang tangguh dan sekaligus ibu dari Nabi Isa. Ia memiliki banyak keistimewaan dan pelajaran yang dapat kita ambil darinya. Pengetahuan tentang tokoh Islam sendiri memang sangatlah minim. Beberapa orang hanya beranggapan bahwa tokoh-toko tersebut hanya akan dibahas pada kajian agama dan tidak dipraktekkan kedalam kehidupan sehari-hari. Padahal, jika mengamalkan apa yang terkandung dalam al-Qur'an, hidup akan menjadi teratur dan terarah. Tujuan dari penelitian ini adalah untuk mengenalkan kembali kepada masyarakat Maryam binti Imran yang mungkin sebagian melupakan atau bahkan tidak tahu menahu tentang hal ini. Metode dalam penelitian ini adalah penelitian pustaka.

Kata kunci: kehidupan, maryam binti imran, sabar, wanita

\section{Pendahuluan}

Saat ini teknologi terus berkembang, Hal ini berdampak mudahnya mendapatkan informasi dari negara luar. Tidak hanya itu, masyarakat juga dapat mengetahui artis yang jaraknya sangat jauh. Salah satu dampak dari mudahnya akses informasi tersebut adalah, kebayakan masyarakat Indonesia mengidolakan artis luar negeri yang di antara mereka, ada yang menerapkan nilai-nilai kehidupan yang bersebrangan dengan prinsip Islam.

Misalnya, generasi muda dengan mudah mengakses informasi terkait berbagai aktifitas artis terkenal hingga mengidolakan mereka. Sehingga sering dijumpai di lingkungan 
sehari-hari di antara generasi itu, ada yang hafal tidak hanya nyanyiannya tapi juga koreografi tariannya.

Hal ini berbanding terbalik dengan aktivitas mereka yang berkaitan dengan ibadah dan kegiatan yang sarat nilai spiritual. Mereka lebih memilih mendengarkan dan menghapal lagu artis idolanya dibandingkan membaca dan menghapal al-Qur'an. Di antarannya juga, mereka lebih mengenal artis-artis itu dibanding tokoh-tokoh teladan yang terekam di dalam al-Qur'an.

Padahal, jika hendak dinilai dari sudut pandang pendidikan pertumbuhan karakter, maka sebagian sebagian kehidupan artis yang diidolakan tersebut bertentangan dengan nilainilia akhlak islami. Sekedar menyebut contoh, kebayakan artis perempuan tidak menutup aurat sesuai ketentuan syariat. mereka bebas menggunakan pakaian yang terbuka yang menampilkan tubuh mereka. Hal seperti ini, tidak dipungkiri, adalah hal yang dilihat dan dicontoh. Ketidak-tepatan mengambil teladan ini diperparah dengan anggapan sebagian orang dewasa yang menilai hal tersebut adalah sesuatu yang biasa dengan alasan bahwa masa mereka memang masa untuk mengeksplorasi berbagai hal.

Sangat banyak tokoh yang diceritakan al-Qur'an yang dapat diambil 'ibrah-nya dan dijadikan teladan. Salah satunya adalah Maryam bin Imran, ibunda Nabi Isa. Perempuan yang menjaga kesuciannya dan hanya beribadah kepada Allah. Wanita yang sabar dalam menghadapi cercaan dari orang-orang disekitarnya kala itu ketika menglahirkan Nabi Isa. Jika mentadabburi kisah beliau di al-Qur'an, akan banyak pelajaran yang didepatkan. melalui penelitian ini akan dibahas ayat-ayat al-Qur'an tentang Maryam binti; menjelaskan apa pelajaran yang dapat diambil serta bagaimana mengaplikasikannya di kehidupan sehari- hari.

\section{Biografi Maryam binti Imran}

Maryam bin 'Imran adalah seorang wanita salihah yang secara khusus Allah sebutkan di dalam al-Qur'an dan menjadi nama surah. Ia hidup sezaman dengan nabi Zakariya yang tidak lain merupakan pamannya. Maryam bin 'Imran berasal dari keluarga 'Imran yang menjadi nama salah satu surah di al-Qur'an. Dari sini dingetahui bahwa Maryam bin 'Imran memiliki latar belakang seorang yang mulia. Keluarga 'Imran adalah orang-orang salih yang tinggal di Nasharat (Nazerat), yakni sebuah tempat utara di Israel. Ayah Maryam bernama 'Imran Yasim yang merupakan seorang imam di Masjid Aqsha, sedangkan ibunda Maryam bernama Hannah binti Yaqudz. 
Dikisahkan, bahwasannya Hannah ibunda Maryam belum dikaruniai anak hingga usia tua. Pada suatu hari ia melihat seekor burung sedang memberi makan anak-anaknya, maka ia pun menginginkan seorang anak. ${ }^{1}$ Maka Hannah pun berdoa kepada Allah dan bersumpah jika diberikan anak, akan dipersembahkan kepada Allah dan diurus di Bait al-Maqdis. Tidak lupa, Hannah berdoa agar anaknya dilindungi dari setan.

Tiba saat Hannah mengandung, 'Imran meninggal dunia. Anak yang lahir itu kemudian dinamakan Maryam binti 'Imran dan dilahirkan di serambi Baitul Maqdis, Maryam sendiri memiliki arti wanita yang rajin beribadah. Setelah itu, Hannah mengadakan undian untuk memilih siapa yang berhak menjadi wali Maryam binti 'Imran yang memang pada saat itu diperebutkan di kalangan Bani Israel karena keistimewaanya. Ternyata undian tersebut dimenangkan oleh Zakariya, yang tidak lain merupakan pama Maryam, sekaligus wali yang memelihara Maryam di Bait al-Maqdis. Dalam tafsir Ibnu Kas̄ìr, Zakariya merupakan suami Bibi Maryam dari pihak ibu.

Hari-hari Maryam bin 'Imran dihabiskan di sebuah bilik yang terletak di sudut Bait alMaqdis. Ia selalu beribadah dan berdzikir kepada Allah. Ketika Nabi Zakariya mengantarkan makanan kepada Maryam, Nabi Zakariya mendapati bahwa telah tersedia buah-buahan dan aneka makanan yang ada di bilik tersebut. Sebagaimana dalam firman Allah: ${ }^{2}$

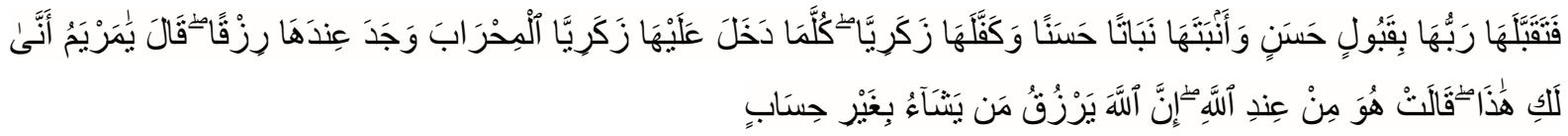

Maka Tuhannya menerimanya (sebagai nazar) dengan penerimaan yang baik, dan mendidiknya dengan pendidikan yang baik dan Allah menjadikan Zakariya pemeliharanya. Setiap Zakariya masuk untuk menemui Maryam di mihrab, ia dapati makanan di sisinya. Zakariya berkata: "Hai Maryam dari mana kamu memperoleh (makanan) ini?" Maryam menjawab: "Makanan itu dari sisi Allah". Sesungguhnya Allah memberi rezeki kepada siapa yang dikehendaki-Nya tanpa hisab. (Ali 'Imran: 37)

Dikisahkan dalam sebuah riwayat bahwa ketika Maryam binti 'Imran beranjak dewasa ia pun pulang ke kampung halamanya di Nasharat. Di sini Maryam didatangi oleh Malaikat Jibril yang datang dalam sosok laki-laki dewasa dan mengabarkan kepada Maryam

\footnotetext{
1 Shafiyyurrahman Al-Mubarakfuri, Shahih Tafsir Ibnu Katsir Jilid 3, ed. Abu Ihsan Al-Atsari (Bogor: Pustaka Ibnu Katsir, 2009), 153.

${ }^{2}$ Abu Fatiah Al-Adnani, Nabi Isa Alaihis Sallam Akan Turun di Langit Damaskus (Surakarta: Granada Mediatama, 2016), 22.
} 
binti 'Imran bahwa ia akan memiliki anak. Maryam pun merasa takut sekaligus kebingungan karena ia merasa tidak melakukan hubungan intim dengan lelaki manapun seperti selayaknya seorang wanita yang hamil. Di sini, Allah kemudian menunjukkan kuasa-Nya yang dengan mudah menghadirkan janin dalam kandungan Maryam binti 'Imran walaupun tidak tersentuh oleh lelaki manapun.

Setelah beberapa waktu kemudian, Maryam kembail ke Yerusalem dalam keadaan mengandung. Pada saat itu, mulai bermunculan fitnah-fitnah yang dilontarkan oleh masyrakat terkait kehamilannya. Mereka menyakini bahwa Maryam adalah wanita yang suci yang tidak memiliki suami lalu bagaimana bisa mengandung? Masyarakat mulai memandang dia adalah seorang yang telah berzina. Saat itu juga keimanan Maryam binti 'Imran sedang diuji. Maryam binti 'Imran tetap sabar dan selalu beribadah kepada Allah walaupun dicerca oleh masyrakat. Saat kehamilannya mendekati masa purna, Maryam menerima wahyu bahwa Allah memerintahkannya untuk pergi menuju tempat yang jauh.

Maryam binti 'Imran pun melaksanakan perintah tersebut, hingga ia sampai di suatu tempat di Betlehem, sebuah kota Palestina di tepi Barat (kini) pada masa kekuasaan raja Herodes Romawi. ${ }^{3}$ Masa hamil tua dan menunggu waktu melahirkan merupakan fase yang sangat berat bagi wanita. Dalam rangka meringankannya, Allah mengutus kembali Malaikat Jibril untuk memberikan kabar gembira kepada Maryam binti 'Imran. Kedatangan Malaikat Jibril tersebut mulai menentramkan Maryam dan membuatnya tegar serta menguatkan keimanannya. Maryam pun bersandar di bawah sebuah pohon kurma yang tengah berbuah dan matang. Atas mukjizat yang Allah berikan, Maryam cukup sedikit menggoyang pohon kurma tersebut untuk menjatuhkan buah yang telah matang.

Nabi Isa lahir di bawah pohon kurma yang Maryam goyangkan. Pasca melahirkan, Ia membawa Nabi Isa untuk menemui masyarakat. Masyarakat pun terkejut melihat hal tersebut, mereka heran dikarenakan melihat Maryam melahirkan anak tanpa suami. Maryam pun hanya diam sembari menunjukkan Nabi Isa kecil kepada mereka dan menyuruh mereka untuk bertanya langsung perihal apa yang mereka herankan. Dengan kuasa-Nya, Nabi Isa yang baru lahir langsung dapat berbicara dan menjelaskan hakikat yang sesungguhnya.

Terkait kisah Maryam binti 'Imran mengandung Nabi Isa, Karel Steenbrink dalam bukunya yang berjudul dalam bahasa Inggri yaitu The Jesus Verses of The Qur'an menggambarkan bahwa pertama kali Jibril meniup ke dalam pakaian (blus atau jaket) yang

\footnotetext{
${ }^{3}$ Sami bin Abdullah Al-Maghlouth, Atlas Sejarah Para Nabi \& Rasul, ed. Qasim Shaleh (Jakarta Timur: Almahira, 2014), 178.
} 
telah dilepaskan oleh Maryam dan ketika Maryam memakai kembali pakaiannya tersebut saat itulah Maryam mulai mengandung. ${ }^{4}$

\section{Ayat Al-Qur'an Tentang Maryam binti Imran}

Setidaknya ada tiga surah di dalam al-Qur'an yang memuat kisah Maryam binti Imran. Ketiga surat itu adalah Ali Imran, Maryam dan at-Tahrim. Berikut ayat-ayat dari ketiga surat tersebut dan tafsirnya:

1. Ali -Imran:

a. Ayat 36

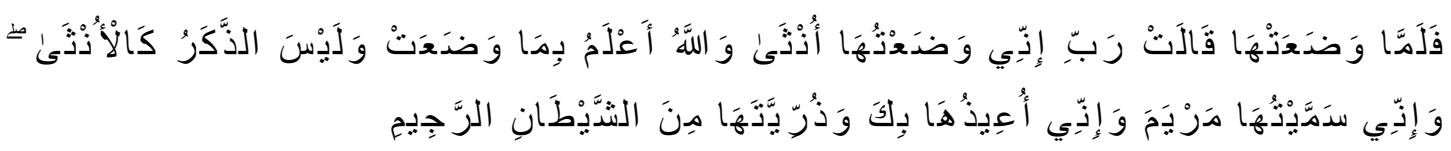

Maka tatkala isteri 'Imran melahirkan anaknya, dia pun berkata: "Ya Tuhanku, sesungguhnya aku melahirkannya seorang anak perempuan; dan Allah lebih mengetahui apa yang dilahirkannya itu; dan anak laki-laki tidaklah seperti anak perempuan. Sesungguhnya aku telah menamai dia Maryam dan aku mohon perlindungan untuknya serta anak-anak keturunannya kepada (pemeliharaan) Engkau daripada syaitan yang terkutuk".

b. Ayat 42

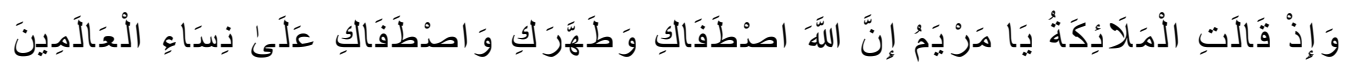

"Dan (ingatlah) ketika Malaikat (Jibril) berkata: "Hai Maryam, sesungguhnya Allah telah memilih kamu, mensucikan kamu dan melebihkan kamu atas segala wanita di dunia (yang semasa dengan kamu)".

\section{c. Tafsir}

Allah memilihkan Maryam sebuah kedudukan paling luhur. Sebab Allah menjadikan Maryam lahir di tengah keluarga yang paham agama dan taat beribadah. Hingga saat lahir, Maryam berada di bawah asuhan Zakariya yang merupakan seorang Nabi. Ayat ini sebagai pemberitaan dari Allah terkait kata-kata yang disampaikan para malaikat kepada Maryam atas perintah Allah, bahwa alasan Allah memilih Maryam adalah karena ia banyak beribadah, berdzikir, zuhud dan suci dari berbagai kotoran jiwa dan waswas.

\footnotetext{
${ }^{4}$ Karel Steenbrink, Nabi Isa dalam Al-Qur'an: Sebuah Interprestasi Outsider atas Al-Qur'an, ed. Sahiron Syamsuddin dan Fejriyan Yazdjird (Yogyakarta: Suka Press, 2015), 178.
} 
Maksud dari kata "menyucikanmu" yaitu menyucikan dari akhlak - akhlak tercela dan memberimu sifat-sifat baik. ${ }^{5}$ Sedangkan maksud kesucian Maryam adalah kesucian dirinya keimanan yang kuat kepada Allah, suci dari kekafiran dan kemaksuatan, juga suci dari sentuhan laki-laki secara mutlak. Suci dari tuduhan Yahudi, karena Allah membebaskannya dari segala tuduhan dan kebohongan yang mereka lontarkan.

2. At-Tahrim

a. Ayat 12

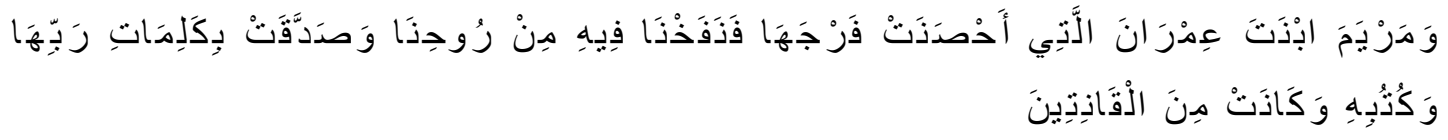

“dan (ingatlah) Maryam binti Imran yang memelihara kehormatannya, maka Kami tiupkan ke dalam rahimnya sebagian dari ruh (ciptaan) Kami, dan dia membenarkan kalimat Rabbnya dan Kitab-KitabNya, dan dia adalah termasuk orang-orang yang taat."

\section{b. Tafsir}

Surah At-Tahrim sendiri dibuka dengan kisah rumah tangga Nabi Muhammad saw. Dalam surah At-Tahrim Allah menyebutkan kisah perempuan yang saleh dan tidak saleh. Dari golongan perempuan yang tidak saleh, Allah menyebutkan kisah istri Nabi Nuh dan Luth, keduanya merupakan istri yang kafir. Adapun kisah perempuan yang saleh, Allah sebutkan kisah istri Fir'aun kemudian Maryam binti 'Imran. Surah ini juga menjadi kesaksian bahwa Maryam merupakan wanita yang suci dan membantah beberapa tuduhan orang kafir.

Dari surah ini juga para ulama berbeda pendapat terkait apa yang dimaksud "meniupkan ruh" dan seperti apa prosesnya. Satu pendapat mengatakan bahwa malaikat Jibril memegang kerah baju Maryam dan meniupkan ruh tersebut kemudian Maryam pun mengandung. Pendapat lain menyatakan bahwa meniupkan di sini melalui kemaluan Maryam binti 'Imran. Pendapat kedua ini yang dinilai lebih kuat. ${ }^{6}$ Walaupun demikian, kiranya tidak perlu terlalu dalam membahas hal tersebut dikarenakan tidak ada nash-nash yang terperinci menjelaskan hal tersebut.

\footnotetext{
${ }^{5}$ Ali Muhammad Al-Shallabi, Isa bin Maryam, ed. Umar Mujtahid (Jakarta Timur: Ummul Qura, 2020), 156.

${ }^{6}$ Ibid., 198.
} 
Sedangkan penyembutan "ruh" memiliki beberapa arti yaitu sesuatu yang ada pada hidup seseorang. Dapat diartikan juga sebagai jiwa, Al-Qur'an dan wahyu. ${ }^{7}$ Tetapi melihat bahwa setelah ditiupkan ruh oleh malaikat Jibril maka Maryam pun hamil, menurut hemat penulis makna ruh dalam surah ini adalah jiwa.

3. Maryam

a. Ayat $27-33^{8}$

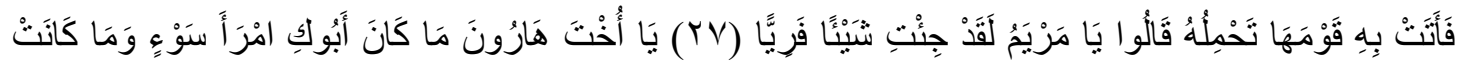

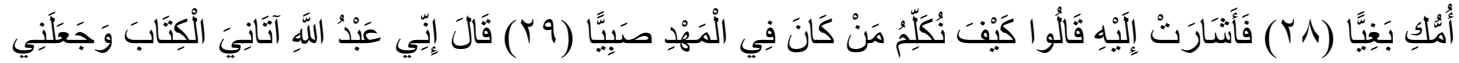

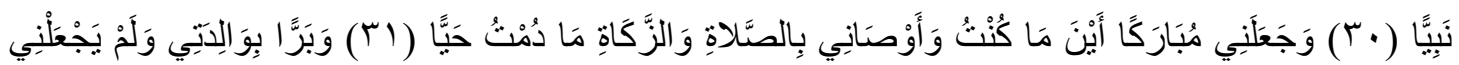

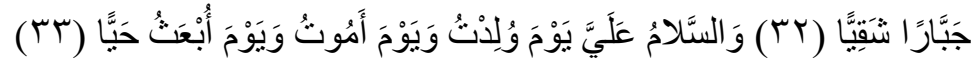

Maka Maryam membawa anak itu kepada kaumnya dengan menggendongnya. Kaumnya berkata, "Hai Maryam, sesungguhnya kamu telah melakukan sesuatu yang amat mungkar. Hai saudara perempuan Harun, ayahmu sekali-kali bukanlah seorang yang jahat dan ibumu sekali-kali bukanlah seorang pezina, " maka Maryam menunjuk kepada anaknya. Mereka berkata, "Bagaimana kami akan berbicara dengan anak kecil yang masih dalam ayunan?" Berkata Isa, "Sesungguhnya aku ini hamba Allah, Dia memberiku Al-Kitab (Injil) dan Dia menjadikan aku seorang nabi, dan Dia menjadikan aku seorang yang diberkati di mana saja aku berada, dan Dia memerintahkan kepadaku (mendirikan) salat dan(menunaikan) zakat selama aku hidup; dan berbakti kepada ibuku, dan Dia tidak menjadikan aku seorang yang sombong lagi celaka. Dan kesejahteraan semoga dilimpahkan kepadaku, pada hari aku dilahirkan, pada hari aku meninggal dan pada hari aku dibangkitkan hidup kembali."

b. Tafsir

Kata Fariyā فريا memiliki arti yang sangat mungkar ${ }^{9}$ atau bisa juga diartikan dengan sesuatu yang merusak. ${ }^{10}$ Kemudian kata بغ baghiyya bermakna seorang

7 Ibrahim Unayas dan Abdul Halim Muntashir, Al-Mu'jam Al-Wasith (Kairo: Maktabah Al-Syuruq AlDawliyah, 2004), 380.

${ }^{8}$ Surat Maryam sendiri digolongkan sebagai surat makkiyyah, kecuali ayat 58 dan 71 yang dimasukkan ke kategori madaniyyah. Relevansi dengan surah sebelumnya yaitu Al-Kahfi di antaranya, bahwa surah ini mempunyai kandungan yang serupa, yaitu keajaiban - keajaiban kisah, seperti kelahiran Yahya dan kisah kelahiran Isa. Ahmad Mushtafa Al-Maraghi, Tafsir Al-Maraghi Jilid 16, ed. Bahrun Abu Bakar (Semarang: PT. Karya Toha Putra, 1993), 49.

${ }^{9}$ Departemen Agama RI, Al-Qur'an dan Tafsirnya Jilid 10 (Jakarta: Widya Cahaya, 2011), 52.

${ }^{10}$ Unayas dan Muntashir, Al-Mu'jam Al-Wasith, 686. 
pezina. Lalu pada ayat 27, Allah memerintahkan kepada Maryam binti Imran untuk berpuasa setelah melahirkan Nabi Isa dan tidak berbicara kepada siapapun. Maryam menyerahkan seluruh nasibnya hanya kepada Allah karena Allah menjamin akan memelihara kehormatannya. Karena Allah ingin membungkam semua yang meragukan kesucian Maryam melalui ucapan Nabi Isa saat bayi. ${ }^{11}$ Setelah itu Maryam pun menggendong Nabi Isa dan membawa ke tengah kaumnya. Maka kaumnya mulai mencela Maryam. Ayat 28, kemudian tidak sampai di situ, mereka mencela Maryam binti Imran dan menuduhnya telah berzina dikarenakan melahirkan anak tanpa suami.

Dilanjutkan pada ayat 29, mendengar hal tersebut Maryam binti Imran hanya berdiam tidak mengucapkan satu kata apapun karena ia telah bernazar untuk tidak berbicara kepada siapapun. Kemudian Maryam menunjuk putranya yang masih bayi dan berada di gendonggannya. Melihat hal tersebut orang Yahudi merasa bahwa Maryam sedang mengolok-olok mereka.

Pada ayat ke-30, Nabi Isa yang masih berada di gendongan ibunya pun berkata "Sesunguhnya aku ini hamba Allah, Dia yang akan memberikan aku kitab suci Injil dan Dia yang menjadikan aku seorang Nabi”. Ucapan ini termasuk menjelaskan bahwa Maryam benar-benar wanita yang suci, tidak seperti yang dituduhkan kaumnya kepada Maryam. Karena soerang Nabi harus dari keturunan orang yang suci dan saleh.

Lalu pada ayat ke 31 Selanjutnya Nabi Isa mengatakan, Allah akan menjadikan akun seorang yang diberkati di mana saja aku berad, karena aku memberi manfaat kepada manusia dan memberi petunjuk kepada mereka ke jalan kebahagiaan; Allah telah memerintahkan aku untuk mendirikan salat karena dalam mendirikan salat itu terkandung perbuatan membersihkan diri dari berbagai macam doa lahir dan batin, Allah juga memerintahkn aku untuk menunaikan zakat selama aku hidup di dunia. Zakat bertujuan untuk membersihkan harta, jiwa dan memberi bantuan kepada fakir miskin.

Ayat 32 dan 33, Nabi Isa pun menjelaskan lebih lanjut, bahwa Allah memerintahkan untuk dirinya berbakti kepada ibunya, tunduk dan selalu berbuat baik kepadanya. Hal ini menunjukkan dan menguatkan bahwa Maryam adalah perempuan yang suci dan terbebas dari segala tuduhan yang dilontarkan oleh kaumnya. Kemudian Nabi Isa melanjutkan "Allah tidak menjadikan aku seorang yang sombong

${ }^{11}$ M. Quraish Shihab, Tafsir Al Mishbah Jilid 8 (Jakarta: Lentera Hati, 2005), 172. 
karena aku selalu taat menyembah Allah dan tidak pula menjadikan akun seorang yang celaka karena aku selalu berbuat baik kepada ibuku"

Selanjutnya Nabi Isa berdoa "Dan kesejahteraan semoga dilimpahkan kepadaku, pada hari aku dilahirkan, pada hari aku meninggal dan pada hari aku dibangkitkan hidup kembali". Nabi Isa berdoa terkait tiga peristiwa penting yang terjadi di hidupnya, yaitu hari dimana Nabi Isa dilahirkan, hari dimana ia meninggal dan hari dia akan dibangkitkan kembali.

\section{Keterkaitan Antar Ayat-Ayat}

Setelah memunculkan beberapa ayat pada pembahasan sebelumnya, maka akan dihubungkan ayat-ayat tersebut. Pada surah Ali 'Imran ayat 36 menjelaskan tentang kehamilan Hannah (ibunda Maryam binti Imran) hingga akhirnya ia melahirkan Maryam. Kemudian pada surah yang sama ayat 42 menjelaskan bagaimana malaikat Jibril menyampaikan kabar gembira kepada Maryam bahwa ia telah dipilih oleh Allah sebagai wanita yang istimewa. Kemudian pada surah Al-Tahrim ayat 12 menjelaskan tentang peniupan ruh kedalam rahim Maryam binti 'Imran dan sebagai saksi bahwa Maryam binti 'Imran merupakan wanita yang suci. Kemudian pada surah Maryam ayat 27-36 menjelaskan bagaimana Maryam menghadapi kaumnya ketika mengandung Isa hingga ia melahirkan.

Dari sini dapat diketahui bahwa ayat-ayat dalam al-Qur'an memiliki hubungan antara ayat yang sebelumnya dan ayat sesudahnya. Walaupun surah yang menjelaskan awal kisah suatu kejadian terletak setelah surah yang menjelaskan kejadian setelahnya. Sebagai contoh surah Al-Tahrim yang menjelaskan peniupan ruh urutannya setelah surah Maryam yang merupakan kisah saat Maryam mengandung dan melahirkan.

\section{Nilai dan Prinsip yang Terkandung Dalam Ayat-ayat}

Ketika kita membaca al-Qur'an dan menyelami setiap maknanya maka akan didapatkan banyak pelajaran yang terkandung di dalam al-Qur'an. Mulai dari berhubungan dengan aqidah atau hubungan terhadap Allah hingga hubungan terhadap sesama manusia. Semua hal tersebut telah dijelaskan di dalam al-Qur'an dan akan selalu relevan dengan setiap keadaan, waktu dan tempat. Karena al-Qur'an berasal dari Allah, Allah yang maha Mengetahui setiap keadaan, baik di masa lalu maupun masa depan.

Terkait tentang hikmah yang dapat diambil dari al-Qur'an, juga dapat diambil pelajaran dan hikmah dari kisah Maryam binti Imran melalui ayat-ayat yang telah disebutkan 
di atas. Di dalamnya terdapat kisah Maryam sehabis melahirkan Nabi Isa dan membawa Nabi Isa dalam gendongannya kepada kaumnya tetapi ia malah mendapatkan celaan.

Berikut ini pelajaran atau ibrah yang dapat diambil dari ayat - ayat tersebut yang telah peneliti susun:

\section{Wanita Yang Menjaga Kesucian Dirinya}

Maryam binti Imran adalah perempuan yang sangat menjaga kesucian dirinya dan menjaga izzah. Sebagaimana yang Allah firmankan dalam Surah al-Tahrim: 12. Perempuan yang saat malaikat Jibril berwujud laki-laki yang tampan, ia Maryam menundukkan pandangannya karena takut kepada Allah dan tergoda oleh setan. 'Iffah adalah menahan, artinya menahan diri sepenuhnya dari sesuatu yang Allah larang, termasuk menjaga pandangan dari laki-laki yang bukan mahram. ${ }^{12}$ Pada kisah Maryam dapat diambil pelajaran bahwa Maryam menjauhi dan menahan dari perbuatan yang Allah larang.

2. Sabar dalam Menghadapi Celaan

Sebagian orang memiliki permasalahan baik di lingkungan kerja maupun dengan tetangga. Seringkali beberapa orang ingin menjatuhkan tanpa sebab dengan cara memfitnah dan menyebarkan berita buruk. Tentu pihak yang menjadi korban akan merasa marah dan kesal pada mereka semua. Semua itu memang sesuatu yang berat dijalani sebagai manusia. Dituduh dan menjadi bahan pembicaraan di lingkungan kerja atau rumah, padahal ia tidak melakukan apa yang mereka katakan. Saat itu terjadi, salah satu jalannya adalah berdoa kepada Allah dan mendekatkan dirinya. Tidak lupa pula, membaca al-Qur'an. Tindakan ini hakikatnya dapat ditadaburri dari cerita Maryam, setelah melahirkan Nabi Isa, ia membawa Nabi Isa dalam gendongannya dan membawa kekaumnya. Sontak saja kaumnya menuduh ia sebagai pezina, karena telah melahirkan bayi tetapi tidak memiliki suami. Lantas menghadapi hal itu Maryam hanya berdiam dan menyerahkan semuanya hanya kepada Allah.

Cerita ini secara tersirat membawa pesan kepada tindakan sabar. Sabar menurut Kamus Besar Bahasa Indonesia adalah tahan menghadapi cobaan, yaitu tidak lekas marah, tidak lekas putus asa, tidak lekas pata hati. Sedangkan menurut syara' berati menahan nafsu dari ketergesaan, menahan lisan dari keluhan, dan menahan nggota

${ }^{12}$ Ainul Millah, Wanita Muslimah Di Era Milenial (Solo: Tiga Serangkai, 2020), 29. 
badan dari memukul-mukul pipi dan merobek-robek pakaian atau yang lainnya. ${ }^{13}$ Sikap Maryam yang diam dan tidak membalas tuduhan mereka merupakan salah satu contoh meninggalkan perdebatan, sebagaimana Rasullullah bersabda:

Telah menceritakan kepada kami Muhammad bin Utsman ad-Dimasyqi Abu alJamahir ia berkata; telah menceritakan kepada kami Abu Ka'b Ayyub bin Muhammad as-Sa'di ia berkata; telah menceritakan kepadaku Sulaiman bin Habib al-Muharibi dari Abu Umamah ia berkata, Rasulullah bersabda, "Aku akan menjamin rumah di tepi surga bagi seseorang yang meninggalkan perdebatan meskipun benar. Aku juga menjamin rumah di tengah surga bagi seseorang yang meninggalkan kedustaan meskipun bersifat gurau, Dan aku juga menjamin rumah di surga yang paling tinggi bagi seseorang yang berakhlak baik." (HR. Abu Daud). Kesabaran Maryam bukan tanpa sebab, melainkan atas karunia yang Allah berikan berupa kesabaran. Maryam pun merupakan wanita yang taat beribadah. Di saat Maryam menghadapi celaan dari kaumnya, ia yakin bahwa Allah akan menolongnya dan menjaga kehormatannya.

3. Nabi Isa adalah Hamba Allah dan utusan-Nya

Saat berada dalam gendongan Maryam, Nabi Isa berkata "Sesungguhnya aku ini hamba Allah" hal ini sekaligus membantah orang kafir yang mengatakan bahwa Nabi Isa adalah Tuhan atau anak Tuhan. Nabi Isa adalah seorang Hamba Allah dan utusan Allah sama seperti Nabi Muhammad saw, yaitu seorang Hamba Allah dan utusan Allah. Dapat disimpulkan bahwa seluruh Nabi memerintahkan untuk menyembah Allah.

\section{Mengaplikasikan Dalam Kehidupan Sehari-Hari}

Setelah mengetahui kisah Maryam binti Imran yang Allah ceritakan di al-Qur'an dan mengambil pelajaran dari kisah tersebut. Maka upaua selanjutnya adalah upaya kontekstualisasi dalam rangka dapat diamalkan. Beberapa contoh dalam pengamalan adalah sebagai berikut:

1. Menjadi wanita yang kuat

Dapat dilihat bahwa Maryam binti Imran adalah wanita yang kuat dalam mengahadapi cobaan hidup. Hal ini dapat menjadi refleksi pada diri masing-masing secara personal. Terkadang memiliki masalah dengan rekan kerja, teman atau bahkan

${ }^{13}$ Ibnu Rajab Al-Hambali, Tazkiyatun Nafs, ed. Imtihan Asy-Syafi'i (Solo: Pustaka Arafah, 2019), 101. 
keluarga. Saat menghadapi hal tersebut, hendaknya tidak lupa meminta pertolongan kepada Allah.

2. Menjadi wanita yang terjaga

Saat ini dengan segala kecanggihan teknologi memungkinkan seseorang yang biasa menjadi terkenal dengan hanya sekedar mengunggah foto dirinya ke sosial media atau menari tanpa rasa malu. Dalam mencontoh Maryam yang senantiasa menjaga diri, seharusnya setiap muslim dan muslimah haruslah menjaga murū ah dan rasa malunya dari hal yang hina seperti itu. Kisah Maryam binti 'Imran ketika didatangi malaikat Jibril dalam wujud lelaki dewasa yang tampan memperlihatkan, Maryam takut akan tergoda dan ia memalingkan matanya dari lelaki tersebut.

Kisah tersebut dapat menginspirasi dan dicontoh agar perempuan selalu dalam keadaan terjaga dan memiliki rasa malu. Dengan tidak mengunggah foto pribadi ke sosial media merupakan salah penerapan dari kisah Maryam binti 'Imran dan merasa malu ketika bertemu dengan lawan jenis. Bukan semestinya seorang perempuan berusaha menarik lawan jenis yang bukan mahram dengan menari dan berdandan secara berlebihan.

\section{Selalu berserah diri kepada Allah}

Dalam menghadapi sesuatu, hendaknya disertai dengan berserah diri kepada Allah. Sebab, hal yang tidak mungkin bagi manusoa, bagi Allah adalah sesuatu yang mungkin. Hal ini menunjukkan bahwa, manusia yang sangat lemah sedangkan Allah maha Kuasa. Maryam binti 'Imran ketika menerima berita dari malaikat Jibril ia pun terkejut tetapi ia yakin bahwa hal itu bisa saja terjadi sebab Allah lah yang maha Kuasa.

Saat tertimpa sebuah masalah dalam kehidupan, harus diakui sabar saat itu memang susah. Sifat asli yang tidak menyukai kesusahan dan kesedihan, hal itu adalah wajar. Tetapi sabar dalam menghadapi cobaan dapat dilatih secara terus menerus. Salah satunya adalah selalu mendekatkan diri kepada Allah dan berusaha menahan keluh kesah saat tertimpa musibah. Awalnya memang terkadang secara tidak sadar berkeluh kesah atau bahkan marah, tetapi dengan meminta pertolongan 
kepada Allah agar diberikan rahmat dan taufik-Nya maka dapat menghindari dari berkeluh kesah atau bahkan dapat mencapai ikhlas ketika ditimpa suatu musibah.

4. Hanya menyembah kepada Allah

Salah satu hal terpenting sebagai Muslim adalah hanya menyembah kepada Allah dan tidak mensyirikkan - Nya dengan sesuatu apapun. Syirik merupakan dosa besar yang harus dijauhi. ${ }^{14}$ Maryam binti 'Imran selalu beribadah dan berdzikir kepada Allah. Hari - harinya dihabiskan dengan ibadah. Ia tidak pernah sekalipun mensyirikkan Allah, Allah mensucikan dia dari perbuatan tersebut.

Saat ini banyak sekali kesyirikan yang samar dan tak terlihat bahwa itu adalah sesuatu yang syirik. Bahkan beberapa orangpun tidak menyadarinya dan menganggap itu adalah hal yang baik dan terus melakukannya. Maka wajib bagi setiap Muslim dan Muslimah agar selalu meminta taufik dan rahmat kepada Allah agar diberikan ilmu untuk membedakan itu semua. Karena tidak mungkin mengetahui hal tersebut syirik jika bukan karena ilmu yang Allah berikan.

\section{Kesimpulan}

Dari penjabaran di atas dapat kita simpulkan sebagai berikut :

1. Maryam binti 'Imran merupakan salah satu mukjizat yang Allah berikan kepada seorang perempuan yang bernama Hannah yang sampai usia tua tidak pernah hamil.

2. Latar belakang keluarga Maryam binti 'Imran adalah keluarga yang mulia. Berdasarkan kisah ayahnya, 'Imran merupakan seorang imam.

3. Maryam merupakan perempuan yang mulia dan terjaga dari hal yang mungkar. Terhindar dari segala tuduhan yang dilontarkan kaumnya kepada dirinya saat melahirkan Nabi Isa. Tetapi walaupun ia mendapatkan celaan dari kaumnya, Maryam tetap sabar dan tidak berputus asa dari rahmat Allah.

4. Seluruh Nabi memerintahkan kepada menyembah hanya kepada Allah. Nabi Isa merupakan Hamba Allah dan utusan-Nya. Hal ini menyanggah pendapat orang kafir yang mengatakan bahwa Nabi Isa merupakan Tuhan atau anak Tuhan.

5. Menjadi perempuan yang kuat dalam menghadapi cobaan tidaklah mudah. Setelah meminta pertolongan kepada Allah kita juga harus sering-sering berlatih. Dapat

\footnotetext{
${ }^{14}$ Syaikh Muhammad At-Tamimi, Kitab Tauhid: Pemurnian Ibadah Kepada Allah, ed. Muhammad Yusuf Harun (Jakarta: Darul Haq, 2019), 18.
} 
berlatih dari hal-hal yang kecil, seperti bersabar di tengah kemacetan atau kenakalan anak.

6. Syirik atau menyekutukan Allah merupakan dosa besar.

\section{DAFTAR PUSTAKA}

Al-Adnani, Abu Fatiah. Nabi Isa Alaihis Sallam Akan Turun di Langit Damaskus. Surakarta: Granada Mediatama, 2016.

Al-Hambali, Ibnu Rajab. Tazkiyatun Nafs. Diedit oleh Imtihan Asy-Syafi'i. Solo: Pustaka Arafah, 2019.

Al-Maghlouth, Sami bin Abdullah. Atlas Sejarah Para Nabi \& Rasul. Diedit oleh Qasim Shaleh. Jakarta Timur: Almahira, 2014.

Al-Maraghi, Ahmad Mushtafa. Tafsir Al-Maraghi Jilid 16. Diedit oleh Bahrun Abu Bakar. Semarang: PT. Karya Toha Putra, 1993.

Al-Mubarakfuri, Shafiyyurrahman. Shahih Tafsir Ibnu Katsir Jilid 3. Diedit oleh Abu Ihsan Al-Atsari. Bogor: Pustaka Ibnu Katsir, 2009.

Al-Shallabi, Ali Muhammad. Isa bin Maryam. Diedit oleh Umar Mujtahid. Jakarta Timur: Ummul Qura, 2020.

At-Tamimi, Syaikh Muhammad. Kitab Tauhid : Pemurnian Ibadah Kepada Allah. Diedit oleh Muhammad Yusuf Harun. Jakarta: Darul Haq, 2019.

Departemen Agama RI. Al-Qur'an dan Tafsirnya Jilid 10. Jakarta: Widya Cahaya, 2011.

Millah, Ainul. Wanita Muslimah Di Era Milenial. Solo: Tiga Serangkai, 2020.

Shihab, M. Quraish. Tafsir Al Mishbah Jilid 8. Jakarta: Lentera Hati, 2005.

Steenbrink, Karel. Nabi Isa dalam Al-Qur'an: Sebuah Interprestasi Outsider atas Al-Qur'an. Diedit oleh Sahiron Syamsuddin dan Fejriyan Yazdjird. Yogyakarta: Suka Press, 2015.

Unayas, Ibrahim, dan Abdul Halim Muntashir. Al-Mu'jam Al-Wasith. Kairo: Maktabah AlSyuruq Al-Dawliyah, 2004. 